Bangladesh J. Bot. 48(4): 933-941, 2019 (December)

\title{
ANATOMY AND DEVELOPMENT OF GYNOECIUM IN TAPISCIA SINENSIS OLIV. AND ITS IMPLICATIONS FOR THE ORIGIN OF CARPELS
}

\author{
Guiliang Xin, XiLu Ni and Wenzhe LiU \\ School of Life Sciences, Northwest University, 229 Taibai Bei Road, Xi'an 710069, China \\ Keywords: Tapiscia sinensis, Anatomy, Amphicribral vascular bundle, Gynoecium development, \\ Origin of carpels
}

\begin{abstract}
Tapiscia sinensis Oliv. (Tapisciaceae) is a rare tree endemic in China. Characteristic of its androdioecy is the coexistence of male and hermaphroditic flowers. Its bisexual flower bears five stamens surrounding the gynoecium, which is composed of a terminal style and an ovary at the base. The style has a bifid stigmata, which is hollow and longer than stamens. The ovary is syncarpous, unilocular, formed by two fused carpels, with a basal or subbasal placenta. Ovule is bitegmic, anatropous, borne on the placenta and supplied by an amphicribral vascular bundle arising directly from receptacle. The carpel wall is supplied by a collateral vascular bundle. The ovule's position changes from initially inserted on the ovary base to later attached to the middle of the ovary wall due to unequal growth of the embryo sac. Based on the present observation and others, the implications of vascular system in Tapiscia for the evolution of carpel are discussed.
\end{abstract}

\section{Introduction}

Tapiscia Oliv. was published as a monotypic genus by Oliver in 1890, based on the specimens collected in Sichuan Province, China. Tapiscia sinensis (Tapisciaceae) (APG IV 2016), an endemic and rare tree under protection in China, is distributed south of the Yangtze River and in southwestern provinces of China as well as the north of Vietnam (Di and Yu 1989). T. sinensis is a relic plant surviving the tertiary glaciations and is a woody perennial androdioecious species with male and hermaphrodite individuals in the population. The male and hermaphroditic flowers blossom at the same time and both of them produce viable pollen. The mean pollen germination rate for males was higher than that of the hermaphrodites on the culture medium with $10 \%$ sucrose (Lü and Liu 2010, Ma 2013). The flower and fruit grow synchronously on the hermaphroditic individuals of T. sinensis (Liu et al. 2008, Lü and Liu 2010). Existence of males may be a balance for a trade-off between resource allocation to flower development and fruit growth at the same time on the hermaphroditic plant, producing excellent pollen for population, and the stamens of hermaphrodites may be a reproductive assurance and reward for pollinators (Zhou et al. 2016, Yang et al. 2017). Previously morphological and anatomical changes of flower and fruit in T. sinensis was investigated (Liu et al. 2008). The dormancy of zygote and fruit maturation until the second year in T. sinensis supports that Tapiscia should be raised to family level. T. sinensis has developed a set of unique strategies to survive from long winter with its naked ovary (undeveloped young fruit) (Teng and Liu 2009). Despite intensive effort, the unique reproductive feature of angiosperms, carpel, and its derivation from the counterparts in gymnosperms remains enigmatic. New researches showed that placenta and foliar part in female units of angiosperms are two parts supplied by two vascular bundles of different organizations, derived from two former primordia controlled by two different sets of genes (Zhang et al. 2017b). The carpel is a complex organ composed of branches and leaves, and ovules are borne on branches (Fu et al. 2018, Liu and Wang 2018). If a theory of carpel origin is practical, then it should also be applicable for Tapiscia,

*Author for correspondence: <lwenzhe@ nwu.edu.cn>. 
which is a member of angiosperms, and Tapiscia should also shed some light on this problem. In the present study, the development and anatomy of the carpel of $T$. sinensis in the hope of providing new insights on the origin of carpel were investigated.

\section{Materials and Methods}

Flower buds and fructifications at various developmental stages were collected from 5 hermaphrodites of Tapiscia sinensis cultivated on the campus of the Northwest University, Xi'an, Shanxi, China in 2011. The materials were fixed with FAA and then used in the preparation of 8 $\mu \mathrm{m}$ thick paraffin sections following the routine methods (Ruzin 1999). Part of the paraffin sections was stained with Safranin $\mathrm{O}$ and Fast Green, critically examined and photographed using a Nikon Eclipse 50i microscope with a Nikon DS-Fil digital camera. The other paraffin sections were stained with Aniline Blue, examined and photographed after excitation at $365 \mathrm{~nm}$ with a Leica DML epifluorescence microscope with a Leica DC300F camera. The longitudinal section of the fruits was observed and photographed using a Nikon D70 Digital Camera, and the flowers were observed and photographed using a Nikon Eclipse 50i microscope with a Nikon DS-Fil digital camera. The figures are organized for publication using Photoshop 7.0. All sections are deposited in the Northwest University, Xi'an, Shanxi, China.

The vascular systems in the ovaries or fruits of hermaphrodites were observed and documented at three levels to investigate the patterns of vascular bundles in carpels and ovules (Fig. 3). S1: cross-sections were made at the base of carpopodium, representing the total vascular system of fruit; S2: cross-sections were made at the joint between the fruits and carpopodium, representing the vascular system in transition before entering the fruits; S3: cross-sections were made at the fruit, representing the placenta vascular bundle and carpel vascular bundle, respectively. After Aniline Blue staining, cell walls of the vessel elements and callose in the sieve plates and sieve tubes appeared brighter than other tissues in the bundles.

\section{Results and Discussion}

The florescence of Tapiscia sinensis population under study was initiated in late May to early June. After fertilization, the ovary took nearly 17 months to develop into a mature fruit (Liu et al. 2008). Accordingly, flowers and fruits could be observed simultaneously existing on hermaphrodites from May to June (Fig. 1 A). The fruits of the preceding year and the young fruits of the current year grew synchronously on the same branch (Fig. 1B). The hermaphroditic inflorescences were $5-10 \mathrm{~cm}$, very small $(1-2 \mathrm{~mm}$ in diam.), yellowish, and fragrant floret, tightly clustered in contracted inflorescences (Fig. 1 A). Its bisexual flower born five stamens surrounding the gynoecium (Fig. 1 C). The gynoecium was composed of a terminal style and an ovary at the base. The style had a bifid stigmata, was hollow and longer than stamens (Fig. 1 D, E). Each of the hermaphroditic flowers has an ovary with one ovule. The ovary was syncarpous, unilocular, formed by two fused carpels, with a basal or sub-basal placenta (Fig. 1 F).

As seen in the longitudinal sections of ovaries collected from June to next March, ovule in hermaphroditic flowers was bitegmic, anatropous, borne on the placenta. The outer integument was shorter than inner integument, which forms the micropyle. Nucellus is composed of $4-6$ cells under the integument (Fig. 1 D, 2 A). After fertilization, most of nucellar cells are disintegrated gradually to provide the nutrition for the embryo sac's development, but the nucellar cells next to chalaza end are split and reproduced (Fig. 2 B), resulting in an expanded apophysis that remains static until the seed becomes mature in the coming year (Fig. 2C, D). The ovule's position changes from initially inserted on the ovary base to later attached to the middle of the side ovary wall, due to unequal growth of the embryo sac. Therefore, the spatial relationship between expanded apophysis and micropyle are different from their original opposite position (Fig. 2 A, D). 

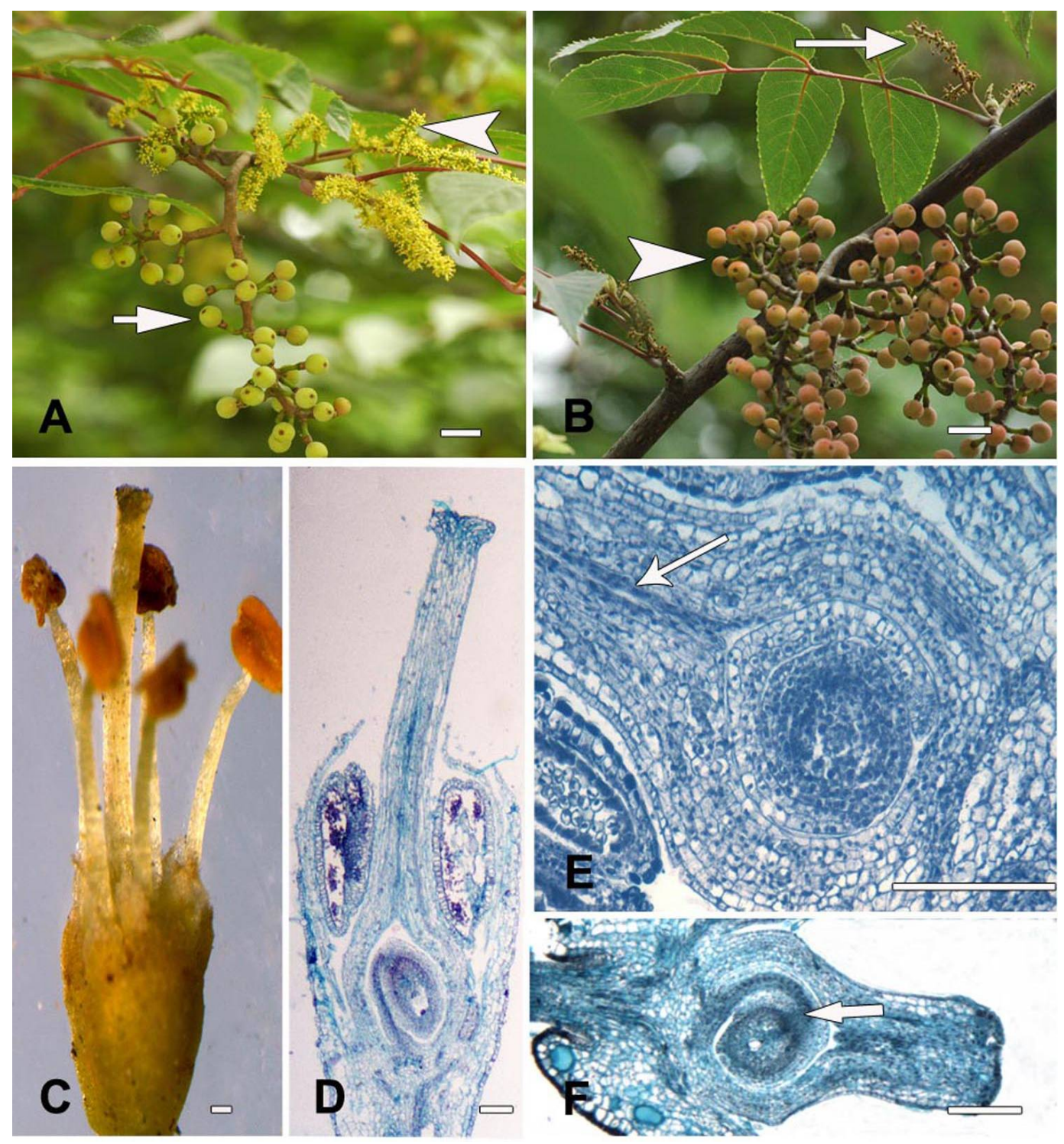

Fig. 1. Flower and inflorescence of T. sinensis. (A) Flowers (arrow) and fruits (arrow head) co-exist on the same hermaphroditic plant; Bar $=1 \mathrm{~cm}$. (B) Maturing fruit of the preceding year (arrow head) and young fruit of the current year (long arrow) exist on the same branch; Bar $=1 \mathrm{~cm}$. (C) The hermaphroditic flower showing stamens; Bar $=1 \mathrm{~mm}$. (D) The longitudinal section of ovary in a hermaphroditic flower; Bar $=20 \mu \mathrm{m}$. (E) Hermaphroditic flower has a hollow and longer style (long arrow); Bar $=20 \mu \mathrm{m}$. (F) Hermaphroditic flowers have an ovary with one ovule, with a basal placenta; Bar $=20 \mu \mathrm{m}$.

The total vascular system of fruits at S0 level was an amphicribral bundle, which had its vessel elements surrounded by several sieve elements (Fig. 4A). The transitional vascular system at S1 level was divided into one large central vascular bundle and seven independent vascular bundles at the periphery, separated by ground tissue in between (Fig. 4B, C). The seven peripheral 
vascular bundles gave rise to the dorsal bundles in carpels. The vascular bundles in the carpel wall were typically collateral, namely, with adaxial xylem and abaxial phloem (Fig. 4D). The large central vascular bundle supplied the ovule, ascending to the chalazal end. The placental vascular bundle assumed an amphicribral organization. Taking an eccentric or central position, the vessel elements of the xylem in the placental bundle were surrounded by several bright dots of sieve elements in cross sections (Fig. 4E). In the meantime, several bright dots of sieve elements were observed at both sides of the vessel elements of the xylem in the longitudinal sections of placental bundle (Fig. 4F).

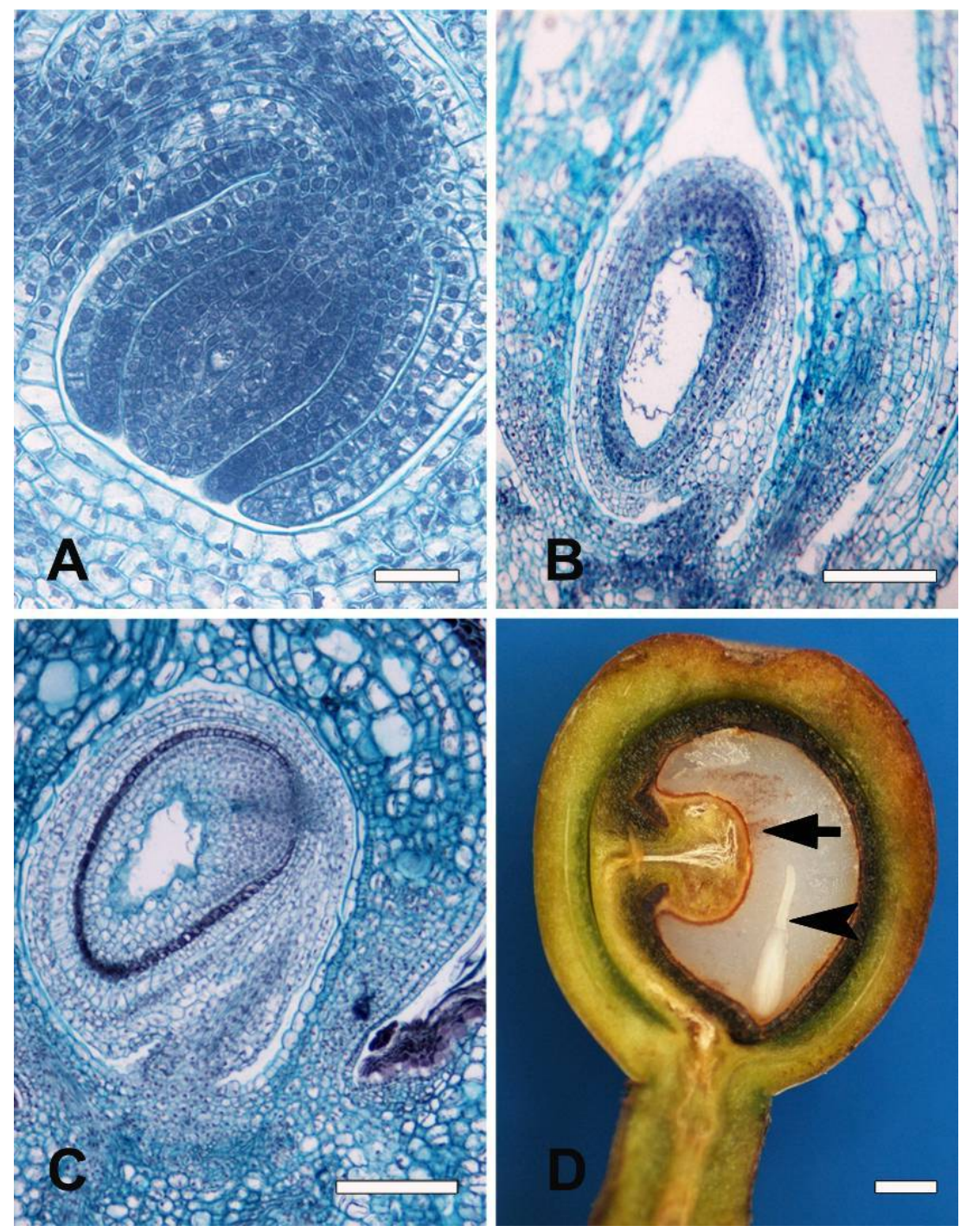

Fig. 2. Anatomy and development of ovule T. sinensis. (A) Anatropous ovule in blossoming, borne on a basal or subbasal placenta; Bar $=50 \mu \mathrm{m}$. (B) Anatropous ovule after fertilization; Bar $=50 \mu \mathrm{m}$. (C) Anatropous ovule during dormant period; Bar $=50 \mu \mathrm{m}$. (D) Anatropous ovule in mature fruit, attached to the middle of the ovary wall; Bar $=50 \mu \mathrm{m}$. 
Tapiscia sinensis is a rare endemic tree, living in highly disturbed habitats. Once-contiguous population of Tapiscia has been broken into a few increasingly isolated populations. The extremely long reproductive cycle (lasting 17 months) of $T$. sinensis is an important trait of androdioecy. This phenomenon is very common in gymnosperms, but extremely rare in angiosperms (Chen and Lu 2001, Liu et al. 2008). After fertilization, the receptacle of hermaphrodite flower begins to expand and extend downwards; as a result, the receptacle gradually wraps the carpopodium. This structure is similar to fleshy seed collar of Podocarpus in gymnosperms (Florin 1958). These obvious changes of the dormant young fruit and other characteristics are adapted to the survival of dormant zygophase in winter (Teng and Liu 2009). During the process of fruit development, nucellus cells at the chalaza form a semicircle globular structure. It is possible that unequal growth of the embryo sac plus fusion of eccentric funiculus with ovary wall together contribute to the changes. The expanded apophysis moves aside continuously, therefore, the expanded apophysis and micropyle are finally vertical to each other, differing from their original opposite position. Vascular bundles are dispersed in hypostase, which helps to enlarge the contact area between expanded apophysis and embryo sac and enhance the transporting capacity of the materials to the embryo sac (Zhang et al. 2004, Zhang et al. 2017a).

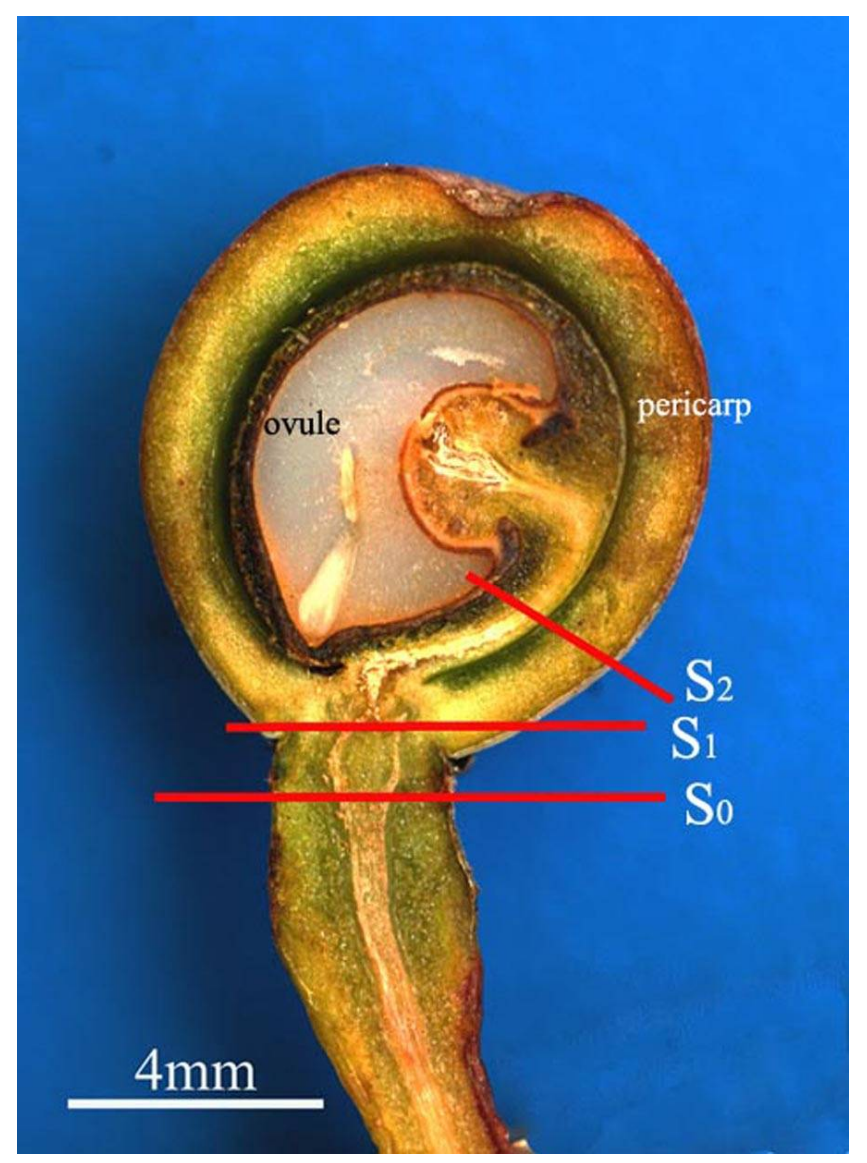

Fig. 3. The longitudinal section of mature fruits, showing the three levels at which the patterns of vascular bundle in carpels and ovules are shown in Fig. 4; Bar $=1 \mathrm{~mm}$. 

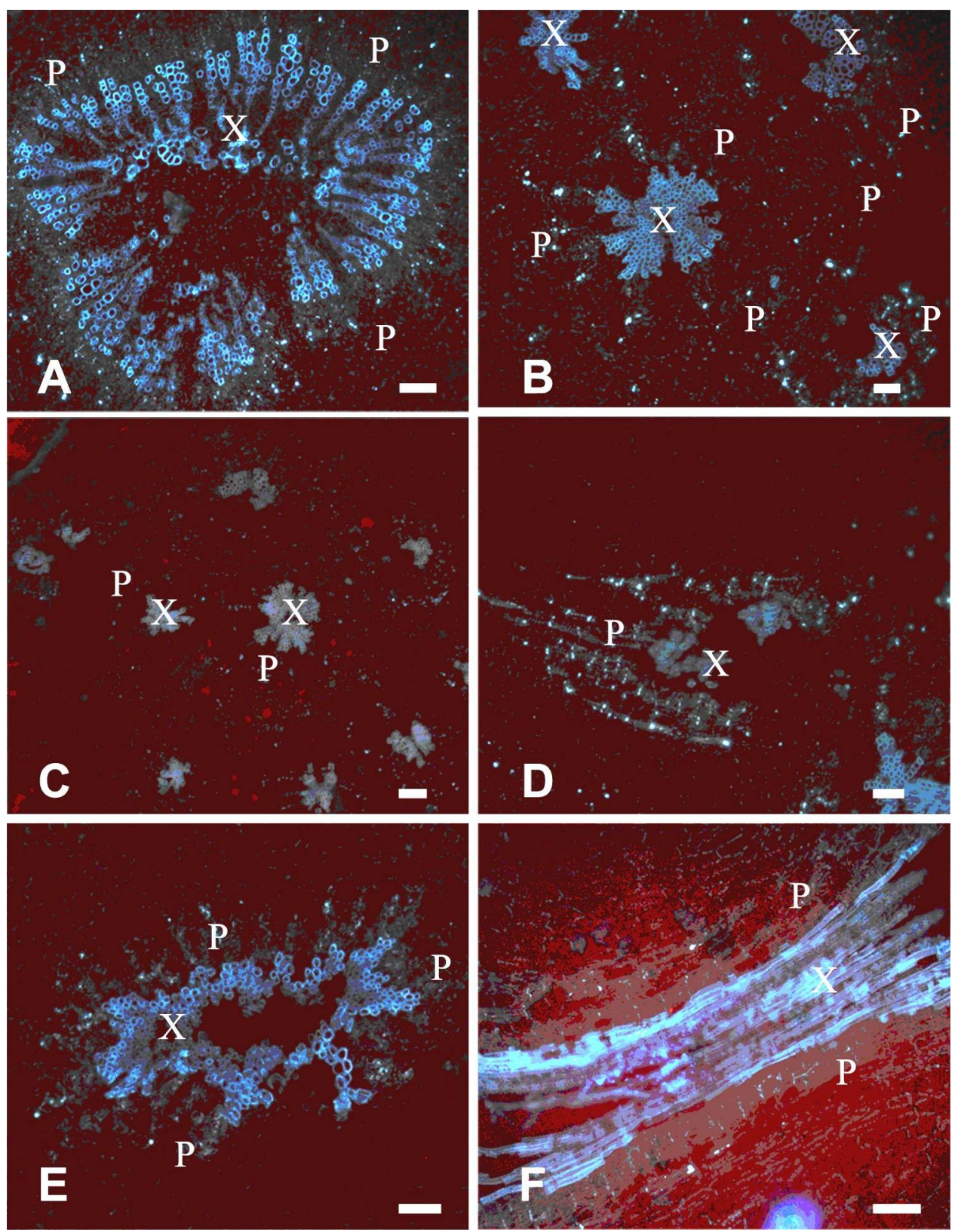

Fig. 4. Anatomy of vascular bundles in gynoecium. (A) The total vascular system of the fruit is an amphicribral bundle, cut at S0 level in Fig. 3; Bar $=10 \mu \mathrm{m}$. (B and C) Vascular system at the joint between the fruits and carpopodium, cut at S1 level in Fig. 3. Showing one large central vascular bundle in B and seven peripheral vascular bundles in C; Bar $=10 \mu \mathrm{m}$. (D - F) Sections were made at the fruit showing the carpel bundles and placental bundles, respectively, cut at S2 level in Fig. 3. (D) A collateral vascular bundle in carpel. (E) Cross-section of an amphicribral vascular bundle in placenta. (F) Longitudinal section of amphicribral vascular bundle in placenta; Bar $=10 \mu \mathrm{m}$. Abbreviations: $\mathrm{P}$ for phloem, $\mathrm{X}$ for xylem and $\mathrm{V}$ for vessel. 
Homology of carpels in angiosperms has been a challenge in botany for long time (Tucker 1975). Many research works have been carried out to investigate whether there are two independent vascular systems in the carpels in the past years (Takhtajan 1969, Cronquist 1988, Thorne 1996). Wang (2010) raised the Unifying Theory, stating that angiosperm carpel is a composite organ derived from an ovule-bearing branch and its subtending bract. In favor of this theory, amphicribral bundles have been documented in placenta of many angiosperms (Dave et al. 1981, Endress and Armstrong 2011). However, comparable information on T. sinensis, crucial for this question, is still lacking. Trying to fill this gap in knowledge, here we investigate the gynoecium development and anatomy of $T$. sinensis.

A carpel as a leaf bearing ovule along its margins as assumed by the traditional interpretation (Cronquist 1988, Sokoloff et al. 2017) is not corroborated by the present research. Our observation indicates that the placenta vascular bundle in $T$. sinensis is distinct from that of the carpel wall's (Fig. 4a). This observation is fully understandable under the light of developmental genetics of model angiosperms, including Arabidopsis, Petunia, and Oryza, in which the developments of carpel wall and placenta are controlled by two exclusive gene sets, implying that placenta is equivalent to a secondary shoot independent of ovary wall (Roe et al. 1997, Skinner et al. 2004, Alvarez-Buylla et al. 2011). This conclusion is further confirmed by the results of gene manipulation on Arabidopsis, in which knocking out the genes controlling carpel wall development has resulted in naked ovules in Arabidopsis, not only turning this model angiosperm into a "gymnosperm", but also re-confirming the independence of ovules and placenta from ovary wall (Rounsley et al. 1995, Roe et al. 1997).

The amphicribral placental bundle of carpopodium and ovule in $T$. sinensis is anatomically distinct from the collateral one: an amphicribral bundle is featured by xylem surrounded by phloem, while a collateral bundle has adaxial xylem and abaxial phloem. This suggests a possible provenance of placental bundle from a former branch. Among angiosperms, amphicribral bundles are restricted to fruits and flowers, closely correlated to the gynoecium of angiosperms (Hu et al. 2010). However, the value of this intimate spatial correlation between amphicribral bundles and gynoecium is rarely explored. An incomplete survey of literature indicates that amphicribral bundles have been documented in the placenta in several families of angiosperms, including Papaveraceae (Kapoor 1973), Leguminosae (Lersten and Don 1966), Solanaceae (Dave et al. 1981), Gesneriaceae (Wang and Pan 1998), Buxaceae (Balthazar and Endress 2002), Annonaceae (Endress et al. 2011), Actinidiaceae (Habart 1974), Myrtaceae and Lythraceae (Schmid 1980). The present new observation (Fig. 4A-F) confirms the amphicribral organization of placental bundle in Tapiscia. The extensive existence of amphicribral bundle in the placenta of the above-listed distantly related clades in angiosperms implies that there is a common feature underlying the placentae in most angiosperms. It is thus logical to hypothesize that placenta in angiosperms is homologous to an ovule-bearing branch.

\section{Acknowledgements}

This research was supported by the National Science Foundation of China (31770413).

\section{References}

Alvarez-Buylla ER, Benítez M and Corvera-Poiré A 2011. Flower development. Arabidopsis Book. 8(3): e0127.

APG IV 2016. An update of the Angiosperm Phylogeny Group classification for the orders and families of flowering plants: APG IV. Bot. J. Linn. Soc. 181: 1-20.

Balthazar M and Endress PK 2002. Reproductive structures and systematics of Buxaceae. Bot. J. Linn. Soc. 140(3): 193-228. 
Chen ZD and Lu AM 2001. Phylogeny and evolution of the Betulaceae. B. Chinese Acad. Sci. 16(3): 188-191.

Cronquist A 1988. The evolution and classification of flowering plants. New York Botanical Garden, Bronx, ed. 2nd, pp 555.

Dave YS, Patel ND and Rao KS 1981. Structural design of the developing fruit of Nicotiana tabacum. Phyton 21: 63-71.

Di WZ and Yu ZY 1989. The first countries to protect rare and endangered plants in Shaanxi Province. Northwest University Press, Xi'an, pp. 200.

Endress PK and Armstrong JE 2011. Floral development and floral phyllotaxis in Anaxagorea (Annonaceae). Ann. Bot. 108(5): 835-845.

Florin R 1958. Notes on the systematics of the Podocarpaceae. Acta Horti Bergiani 17: 403-411.

Fu Q, Diez JB and Pole M 2018. An unexpected noncarpellate epigynous flower from the Jurassic of China. eLife 7: e38827.

Habart JL 1974. La baie de L'Actinidia chinensis Planch. var. chinensis. Fruits 29: 191-207.

Hu ZH, Liu WZ, Cai X, Wu H and Ning XP 2010. Plant anatomy. Higher Education Press, Beijing, pp. 355.

Kapoor LD 1973. Constitution of amphicribral vascular bundles in capsule of Papaver somniferum Linn. Bot. Gaz. 134:161-165.

Lersten NR and Don KW 1966. The discontinuity plate, a definitive floral characteristic of the Psoraleae (Leguminosae). Am. J. Bot. 53: 548-555.

Liu WZ, Kang HQ, Zheng HC and Fen YZ 2008. An investigation on the sexual reproductive cycle in Tapiscia sinensis. J. Sys. Evol. 46(2): 175-182.

Liu ZJ and Wang X 2018. A novel angiosperm from the early cretaceous and its implications for carpel-deriving. Acta Gelo. Sin-Engl. 92(4): 1293-1298.

Lü W and Liu WZ 2010. Pollination biology in androdioecious species Tapiscia sinensis. Chinese Bull. Bot. 45(6): 713-722.

Ma L 2013. Sex allocation when flower and fruit grow synchronously on an androdioecy plant of Tapiscia sinensis (Tapisciaceae). Northwest University Master Thesis, pp. 17-19.

Roe JL, Nemhauser JL and Zambryski PC 1997. Tousled participates in apical tissue formation during gynoecium development in Arabidopsis. Plant Cell 9(3): 335-353.

Rounsley SD, Ditta GS and Yanofsky MF 1995. Diverse roles for MADS box genes in Arabidopsis development. Plant Cell 7(8): 1259-1269.

Ruzin SE 1999. Plant microtechnique and microscopy. New York: Oxford University Press.

Schmid R 1980. Comparative anatomy and morphology of Psiloxylon and Heteropyxis, and the subfamilial and tribal classification of Myrtaceae. Taxon 29(5-6): 559-595.

Skinner DJ, Hill TA and Gasser CS 2004. Regulation of ovule development. Plant Cell 16(suppl_1): S32-45.

Sokoloff DD, Nuraliev MS, Oskolski AA and Remizowa MV 2017. Gynoecium evolution in angiosperms: Monomery, pseudomonomery, and mixomery. Moscow U. Biol. Sci. B. 72(3): 115-127.

Takhtajan A 1969. Flowering plants, origin and dispersal. Edinburgh: Oliver \& Boyd Ltd.

Teng L and Liu WZ 2009. Passing winter strategies of Tapiscia sinensis during its extreme long reproductive cycle. J. Wuhan Bot. Res. 27(1): 70-75.

Thorne RF 1996. The least specialized angiosperms, in Flowering plant origin, evolution \& phylogeny, eds. D.W. Taylor \& L.J. Hickey. (New York: Chapman \& Hall), pp. 286-313.

Tucker SC 1975. Carpellary vasculature and the ovular vascular supply in Drimys. Am. J. Bot. 62: 191-197.

Wang X 2010. The dawn angiosperms. Heidelberg, Springer, pp. 236.

Wang YZ and Pan KY 1998. "Comparative floral anatomy of Whytockia (Gesneriaceae) endemic to China," in Floristic Characteristics and Diversity of East Asian Plants, eds A. L. Zhang, and S. G. Wu (China Higher Education Press, Beijing), pp. 352-366. 
Yang K, Zhou XJ and Wang YY 2017. Carbohydrate metabolism and gene regulation during anther development in an androdioecious tree, Tapiscia sinensis. Ann. Bot. 120(6): 967-977.

Zhang Q, Hao Q and Guo X 2017a. Anther and ovule development in Camellia japonica (Naidong) in relation to winter dormancy: Climatic evolution considerations. Flora 233: 127-139.

Zhang X, Liu W and Wang X 2017b. How the ovules get enclosed in magnoliaceous carpels. PLoS ONE 12(4): e0174955.

Zhang Q, Sodmergen, Hu YS, Lin JX 2004. Female Cone Development in Fokienia, Cupressus, Chamaecyparis and Juniperus (Cupressaceae ). Acta Bot. Sin. 46(9): 1075-1082.

Zhou XJ, Ma L and Liu WZ 2016. Functional androdioecy in the rare endemic tree Tapiscia sinensis. Bot. J. Linn. Soc. 180(4): 504-514.

(Manuscript received on 2 July, 2018; revised on 20 February, 2019) 